\title{
Editorials
}

\section{Should we screen for atrial fibrillation?}

No country has yet established a national screening programme (NSP) for atrial fibrillation (AF), including the UK. However, there is an increasing body of evidence suggesting screening may be beneficial, prompting recommendations from prominent expert bodies to screen for AF. ${ }^{1}$ Despite these data, the UK National Screening Committee (NSC) has not recommended systematic population screening. The review in 2014 concluded

it is not clear that those identified as at risk through screening would benefit from early diagnosis'. ${ }^{2}$ The NSC also identified a need to improve clinical management and standardise the treatment services currently available to those with diagnosed AF. The British Cardiovascular Society issued a subsequent statement in response to the decision questioning the interpretation of the evidence and suggesting that it would be in the public interest to reconsider their decision. ${ }^{3} \mathrm{~A}$ further review by the UK NSC is scheduled for 2017/2018.

\section{MAIN ARGUMENTS FOR ATRIAL FIBRILLATION SCREENING}

$A F$ is the most common cardiac arrhythmia, present in around $1 \%$ of the population and $5 \%$ of those aged $\geq 65$ years. ${ }^{4}$ Approximately 1 million people are diagnosed with AF in England and Wales, and several hundred thousand more may have undiagnosed AF. Data from the US suggest the incidence of AF may double by $2050 .{ }^{5}$

The most important clinical significance of $\mathrm{AF}$ is the associated fivefold increase in the risk of stroke. Furthermore, AF-related strokes tend to be more severe and have higher mortality. ${ }^{6}$ Treatment of AF with anticoagulation is highly effective at reducing this excess risk of stroke. ${ }^{1}$ Population-based screening for AF thus has the potential for consideration as part of a public health initiative, meeting many of the NSC's criteria. It is estimated that 7100 AF-related strokes and 2100 AF-related deaths could be prevented annually in the UK if everyone with AF was appropriately managed.

Several factors have led to an increased interest in AF screening. ${ }^{8}$

Increased prevalence. The prevalence of $A F$ is increasing due to a combination of population ageing, changing patterns of

\section{"[Atrial fibrillation] is the most common cardiac arrhythmia, present in around 1\% of the population and $5 \%$ of those aged $\geq 65$ years.}

risk factors, and improved survival rates in other, contributory forms of cardiovascular disease.

Newer effective treatments. Newer treatments are available in the form of novel oral anticoagulants (NOACS), which are safer, at least as effective as the existing treatment mainstay of vitamin $\mathrm{K}$ antagonists, and simpler to use las they do not require regular blood tests).

Development of relatively inexpensive screening devices. A number of relatively inexpensive screening devices for detecting $\mathrm{AF}$ in the community have been developed and the field may evolve rapidly as new technologies and algorithms emerge.

\section{MAIN ISSUES WITH ATRIAL \\ FIBRILLATION SCREENING}

Although the case for screening is strong, there are several key outstanding issues and in particular:

Lack of evidence. There is a lack of highquality randomised controlled trial (RCT) evidence that screening for silent $A F$ in a high-risk population who may or may not be already interacting with the healthcare system saves lives or reduces morbidity. Is the risk of stroke in someone with screen-detected AF the same as someone with AF detected because of clinical presentation? Although the RCT evidence is lacking, a large UK cohort study showed that untreated incident asymptomatic AF resulted in a stroke rate of $4 \%$ and mortality of $7 \%$ in the first 1.5 years after diagnosis and these patients would not be considered low risk. Oral anticoagulant \pm antiplatelet therapy received by $51 \%$ in the year following diagnosis was associated with adjusted hazard ratio of 0.35 for stroke, and 0.56 for death compared with no therapy.

Is screening for AF cost-effective? Several cost-effectiveness analyses have been published since the NSC report, which conclude that screening is cost-effective. However, they relied on untested assumptions of prognosis and treatment effect in screen-detected $A F$, and on time lag before a screen-detected AF would become diagnosed without screening.

The uptake of anticoagulation for established AF in the UK is poor. Results published in August 2014 in the first report of the Sentinel Stroke National Audit Programme (SSNAP) found that only $36 \%$ of patients with known AF admitted to hospital with a stroke were taking anticoagulants. ${ }^{10}$

Other issues that need considering include:

Workload in general practice. This has increased significantly and thus there are concerns as to whether an AF screening programme would be sustainable. ${ }^{11}$

Many primary care professionals cannot accurately detect AF on an electrocardiogram. Diagnosis of AF in the community needs to factor in the reading of electrocardiograms by appropriately trained people. ${ }^{12}$

\section{"Several factors have led to an increased interest in AF screening ... increased prevalence ... newer effective treatments... [the] development of relatively inexpensive screening devices.}




\section{"Before we can introduce a national screening programme, we need to know from randomised trials whether or not AF screening is effective at reducing cardiovascular morbidity and mortality.}

Should the screening include screening for paroxysmal atrial fibrillation (pAF)? Early results from the STROKESTOP study ${ }^{13}$ suggest that, if pAF is sought, this will greatly increase the yield of screening. However, question marks remain as to whether pAF carries the same stroke risk as permanent $A F{ }^{14}$

\section{CONCLUSIONS}

Before we can introduce a national screening programme, we need to know from randomised trials whether or not AF screening is effective at reducing cardiovascular morbidity and mortality. There are ongoing trials exploring this question in Sweden and the Netherlands, and more are planned. If screening is effective, there are several operational issues that need to be addressed before a national screening programme can be introduced: What is the optimal target population? What is the optimal screening technology? How best to confirm that screen-positive people do have AF? How to ensure fully informed patient choice, both with regard to acceptance of screening, and subsequent treatment if found to have AF?

There is strong potential for public health gain in screening for $A F$, but, as yet, the evidence base is unlikely sufficient for a national programme.

\section{Mark Lown,}

GP and Clinical Lecturer, University of

Southampton, Southampton.

\section{James Garrard}

Academic Foundation Doctor, University of

Southampton, Southampton.

\section{Greg Irving,}

GP and Clinical Lecturer, University of Cambridge, Cambridge.

\section{Duncan Edwards,}

Doctoral Research Fellow, University of Cambridge, Cambridge.

\section{FD Richard Hobbs,}

GP and Professor of Primary Care Health Sciences, University of Oxford, Oxford.

\section{Jonathan Mant,}

Professor of Primary Care Research, University of Cambridge, Cambridge.

\section{Provenance}

Freely submitted; externally peer reviewed.

\section{Competing interests}

Greg Irving sits on the UK National Screening Committee.

DOI: https://doi.org/10.3399/bjgp17X691613

\section{REFERENCES}

1. Kirchhof P. Benussi S, Kotecha D, et al. 2016 ESC guidelines for the management of atrial fibrillation developed in collaboration with EACTS. Eur Heart J 2016; 37(38): 2893-2962.

2. Public Health England or National Screening Committee. The UK NSC recommendation on atrial fibrillation screening in adults. NSC, 2014. https://legacyscreening.phe.org.uk/ atrialfibrillation (accessed 22 May 2017).

3. British Cardiovascular Society. BCS statement on screening for atrial fibrillation to prevent stroke. BCS, 2014. http://www.bcs.com/pages/news_full. asp?NewsID=19792297(accessed 22 May 2017).

4. Fitzmaurice DA, Hobbs FDR, Jowett S, Mant $J$, et al. Screening versus routine practice in detection of atrial fibrillation in patients aged 65 or over: cluster randomised controlled trial. BMJ 2007; 335(7616): 383

5. Atrial Fibrilliation Association and Anticoagulation Europe. The AF report. Atrial fibrillation: preventing a stroke crisis. AFA and ACE, 2011. http://www.preventafstrokecrisis.org/files/files/The\%20AF\%20 Report\%2014\%20April\%202012.pdf laccessed 22 May 2017).

6. Marini C, De Santis F, Sacco S, et al. Contribution of atrial fibrillation to incidence and outcome of ischemic stroke: results from a population-based study. Stroke 2005; 36(6): 1115-1119.

7. Department of Health Cardiovascular Disease Team. Cardiovascular disease outcomes strategy: improving outcomes for people with or at risk of cardiovascular disease. DH, 2013. https://uww.gov.uk/government/ uploads/system/uploads/attachment_data/ file/214895/9387-2900853-CVD-Outcomes

\section{ADDRESS FOR CORRESPONDENCE}

\section{Mark Lown}

Primary Care and Population Sciences, Aldermoor Health Centre, Aldermoor Close, Southampton S016 5ST, UK.

\section{Email: m.lowndasoton.ac.uk}

web1.pdf laccessed 22 May 2017).

8. Healey JS, Sandhu RK. Are we ready for mass screening to detect atrial fibrillation? Circulation 2015; 131(25): 2167-2168.

9. Martinez C, Katholing A, Freedman SB Adverse prognosis of incidentally detected ambulatory atrial fibrillation. A cohort study. Thromb Haemost 2014; 112(2): 276-286.

10. Royal College of Physicians, Clinical Effectiveness and Evaluation Unit on behalf of the Intercollegiate Stroke Working Party Sentinel Stroke National Audit Programme (SSNAP). Acute organisational audit report. 2014. https://uww.strokeaudit.org/ Newspress/SSNAP-Acute-OrganisationalAudit-2014-Public-Repor.pdf laccessed 22 May 2017).

11. Hobbs FD, Bankhead C, Mukhtar T, et al. Clinical workload in UK primary care: a retrospective analysis of 100 million consultations in England, 2007-14. Lancet 2016; 387(10035): 2323-2330.

12. Mant J, Fitzmaurice DA, Hobbs FD, et al. Accuracy of diagnosing atrial fibrillation on electrocardiogram by primary care practitioners and interpretative diagnostic software: analysis of data from screening for atrial fibrillation in the elderly (SAFE) trial. BMJ 2007; 335(7616): 380.

13. Svennberg E, Engdahl J, Al-Khalili F, et al. Mass screening for untreated atrial fibrillation: the STROKESTOP study. Circulation 2015; 131(25): 2176-2184.

14. Vanassche T, Lauw MN, Eikelboom JW, et al. Risk of ischaemic stroke according to pattern of atrial fibrillation: analysis of 6563 aspirintreated patients in ACTIVE-A and AVERROES. Eur Heart J 2015; 36(5): 281-287a. 